\title{
Optimization of process parameters for turning of titanium alloy (Grade II) in MQL environment using multi-Cl algorithm
}

\author{
Apoorva Shastri ${ }^{1} \cdot$ Aniket Nargundkar $^{1}$ (D) Anand J. Kulkarni ${ }^{2} \cdot$ Luigi Benedicenti $^{3}$
}

Received: 18 June 2020 / Accepted: 12 January 2021 / Published online: 27 January 2021

(C) The Author(s) 2021 OPEN

\begin{abstract}
The advancement of materials science during the last few decades has led to the development of many hard-to-machine materials, such as titanium, stainless steel, high-strength temperature-resistant alloys, ceramics, refractories, fibre-reinforced composites, and superalloys. Titanium is a prominent material and widely used for several industrial applications. However, it has poor machinability and hence efficient machining is critical. Machining of titanium alloy (Grade II) in minimum quantity lubrication (MQL) environment is one of the recent approaches towards sustainable manufacturing. This problem has been solved using various approaches such as experimental investigation, desirability, and with optimization algorithms. In the group of socio-inspired optimization algorithm, an artificial intelligence (AI)-based methodology referred to as Cohort Intelligence $(\mathrm{Cl})$ has been developed. In this paper, $\mathrm{Cl}$ algorithm and Multi- $\mathrm{Cl}$ algorithm have been applied for optimizing process parameters associated with turning of titanium alloy (Grade II) in MQL environment. The performance of these algorithms is exceedingly better as compared with particle swarm optimization algorithm, experimental and desirability approaches. The analysis regarding the convergence and run time of all the algorithms is also discussed. It is important to mention that for turning of titanium alloy in MQL environment, Multi-Cl achieved $8 \%$ minimization of cutting force, $42 \%$ minimization of tool wear, $38 \%$ minimization of tool-chip contact length, and $15 \%$ minimization of surface roughness when compared with PSO. For desirability and experimental approaches, $12 \%$ and $8 \%$ minimization of cutting force, $42 \%$ and $47 \%$ minimization of tool wear, $53 \%$ and $40 \%$ minimization of tool-chip contact length, and $15 \%$ and $20 \%$ minimization of surface roughness were attained, respectively.
\end{abstract}

Keywords Cohort intelligence $\cdot$ Multi-Cl algorithm Process parameters · Titanium alloy $\cdot$ Minimum quantity lubrication

\section{Introduction}

Machining is a major industrial activity consisting of various processes in which a raw material is cut to a desired final shape and size by a controlled material removal process. The machining system generally consists of the cutting tool, workpiece and machine tool [10]. The term machinability is broadly used to evaluate the ease with which any type of material can be cut to certain size and shape with specific tolerance, surface integrity, etc., with minimum cost and time [8]. The reasonably good machinability of a material signifies that the material allows higher cutting rates with increased tool life, generation of lower cutting forces during machining and resulting in a satisfied surface and form tolerances. Traditional engineering materials such as steels and aluminium have higher machinability; however, to overcome challenges of the late twentieth century, along with minimizing the weight and cost of the product, improvement in the properties of the existing material also becomes more important. The

Aniket Nargundkar, aniket.nargundkar@sitpune.edu.in; Apoorva Shastri, apoorva.shastri@sitpune.edu.in; Anand J. Kulkarni, anand.kulkarni@sitpune.edu.in; Luigi Benedicenti, luigi.benedicenti@unb.ca|'Symbiosis Institute of Technology, Symbiosis International (Deemed University), Pune, MH 412115, India. ${ }^{2}$ Symbiosis Centre for Research and Innovation, Symbiosis International (Deemed University), Pune, MH 412115, India. ${ }^{3}$ Faculty of Computer Science, 550 Windsor Street, Fredericton, NB E3B 5A3, Canada. 
result of this endeavour was the introduction of new generation of materials and alloys comprising of special characteristics such as higher strength-to-weight ratio, high stiffness and toughness, high heat capacity and thermal conductivity. Some of the prime examples of such new materials are titanium and its alloys, nickel and its alloys, metal matrix composites, superalloys and ceramics, etc. These advanced materials have brought new challenges such as high manufacturing cost and labour intensive process. Moreover, due to the superior characteristics of these materials such as high strength, stiffness and hardness, the manufacturing processes employed for most of the traditionally engineering materials become inefficient and may result into rapid deterioration of the cutting tools, inferior quality of quality of machined parts and may add further rework. According to Kishawy and Hosseini [21] and [10], the major reasons behind these problems are generation of high temperatures and stresses during machining these advanced materials. Hence, these materials are also referred to as difficult to cut materials.

Titanium and its alloys possess characteristics, viz. corrosion resistance, chemical stability or inertness, hot hardness, low density and desired feature such as high specific strength at elevated temperatures. Titanium offers higher strength-to-weight ratio as compared to aluminium and steel. Hence, recently aluminium and steels are being replaced with titanium alloys. Due to high thermal capacity and corrosion resistance, titanium and its alloys have made a huge impact on the petrochemical industry [25]. Automotive industry is another field of application where titanium and its alloys have been widely used. Piston connecting rods, engine valve train, valve springs are some of the examples of titanium products used in automobiles [32]. Aircraft engine parts such as fan case, compressor vanes, and compressor blades have been manufactured with titanium alloys [21]. Unalloyed titanium is used for constructing the airframe of the planes as it withstands with the cryogenic temperatures induced during the flights [18]. Titanium alloys could be machined using a variety of machining processes such as CNC End Milling [48], Abrasive Water Jet Machining (AWJM) [38], Turning [15], Micro-Scale Orthogonal Machining [33], and Laser assisted MicroElectric Discharge Machining (EDM) [5]. Even though the titanium alloys are being widely utilized, there are several challenges associated with the manufacturing aspects of it such as shorter tool life, vibrations and chatters induced, and lower machining productivity $[20,31]$. Several strategies have been developed and implemented to improve the machining efficiency of the titanium. Some notable strategies are developing tool materials and designs [7], optimization of cutting parameters and investigation of machinability [19], developing hybrid machining processes such as laserassisted machining (LAM), minimum quantity lubrication (MQL) and cryogenic machining [17].

It is very common to use cutting fluids in machining operations for achieving higher productivity and enhanced machinability. Usually, cutting fluids are used in the machining for cooling, removal of chips and lubrication. For titanium machining, cutting fluids control the temperature while machining and yield better results in the form of enhanced machining performance and improvement in tool life. However, according to Sharma et al. [44], many cutting fluids are unsafe in the environment safety viewpoint because of their noxiousness and non-environment friendliness. There is necessity to build a sustainable lubrication method that can substitute the traditional flood cooling approach and decrease the high cutting fluid utilization. Hence, nowadays, MQL-based methods are replacing traditional flood cooling methods $[36,47]$. MQL environment contains disintegration of cutting fluid, then uniformly mixed in the air and intended at the cutting edge. The flow rate in MQL system is usually regulated in the range of $50 \mathrm{ml} / \mathrm{hr}$ to $500 \mathrm{ml} / \mathrm{hr}$ [36]. The oil drops in MQL method maintain the cutting temperature by decreasing the friction at the cutting edge. On the other hand, mixed air gives the cooling action for heat dissipation via heat transfer by convection. The MQL method consumes very less quantity of cutting fluid due to its green nature and consumes less energy for pumping $[36,47]$.

The machining performance of titanium has been examined by Niknam et al. [31] using cutting force $F_{c}$, tool wear $V_{\mathrm{Bmax}}$, surface roughness $R_{a}$ and tool chip contact length $L$. The cutting force is directly proportional to the feed rate $f$, whereas it carries inverse relationship with the cutting speed $V_{c}$. The tool angle $\emptyset$ also shows significant effect on the directional cutting forces. Higher cutting forces result into increased power consumption and reduced tool life. To avoid this, cutting forces should be minimized [31]. Titanium alloys have the tendency to react with most of the cutting tool materials and that results into the poor machinability of titanium alloys. The tool failure during machining of titanium alloy is due to the flank wear and excessive chipping on the tool flank edge. Hence, it is necessary to minimize the flank wear $V_{\text {Bmax }}$ during the machining of titanium alloy [11]. Generally low surface quality (higher surface roughness) is resulted in titanium alloys due to poor machinability, and it is important to minimize the surface roughness $R_{a}$ [53]. The tool chip contact length $L$ represents the chip formation mechanism for any machining process. As tool chip contact length increases, surface roughness also increases, and hence it is important to minimize the tool chip contact length $L[31,43]$. 
Optimization of these machining parameters is important to achieve desired product dimensions with minimum cost yielding increased productivity. Earlier, engineers practiced trial-and-error approaches which depend on the experience and intuition to determine initial process parameter settings. However, this approach is not suitable in the context of today's manufacturing processes. Consequently, the optimization of manufacturing process parameters requires new reliable methods and approaches, based on modelling activities, in order to predict the output of the manufacturing processes or in other words to predict the behaviour of the manufacturing process [32]. In order to deliver the sustainable manufacturing approach, it is important to achieve the right combination of these process parameters for machining of titanium alloy in MQL environment. With the addition of MQL approach, the optimization problem becomes complex, and the classical techniques may not be able to optimize the process efficiently. Hence, application of evolutionary algorithms for optimization is a recent approach adopted by several researchers and scientists.

Various algorithms in the soft computing domain, especially inspired from nature such as Genetic Algorithm (GA), Artificial Bee Colony (ABC), and Ant Colony Optimization (ACO) have been applied for optimizing wide variety of engineering applications [6, 30, 39]. Similarly, the optimization techniques inspired from competition and interaction of the societal individuals are referred to as socio-inspired optimization methods. Cohort Intelligence $(\mathrm{Cl})$ algorithm [22] is one of such techniques and its significantly modified version is referred to as Multi-Cl [46].

Sahu and Mahapatra [42] used grey relation-based firefly algorithm for optimization titanium alloy with EDM. Pramanik et al. [37] investigated and minimized geometrical errors produced by Wire EDM of titanium alloy. [1] employed GA for multi-objective optimization of shape memory alloy with Wire EDM. [15] modelled the process through response surface methodology (RSM) and particle swarm optimization (PSO) technique was used for optimizing the machining associated parameters. Revuru et al. [41] experimentally optimized process parameters for tool wear, cutting forces, and surface roughness of titanium machining under varying lubricating scenarios such as dry machining, cutting fluid with and without micro-graphite and cutting fluid based on soybean, with and without graphite. The investigation of turning performance of Inconel 825 alloy using physical vapour deposition-titanium nitrate inserts has been carried out by Tamang et al. [52] focusing sustainable machining. Three aspects of sustainability, viz. cutting power consumption, tool wear, and surface roughness, have been investigated employing dry and MQL machining environment. Three cutting parameters such as cutting speed, cutting feed and depth of cut have been considered. MQL environment has been proved to be the favourable environment for reducing the tool wear and power consumption. Furthermore, multiobjective GA is applied for the simultaneous optimization of cutting power consumption, tool wear and surface roughness. For the application in manufacturing industry, an explicit grid of optimized cutting parameters for obtaining the desired surface finish with minimum tool wear and power consumption is discussed. The milling of Ti-6AI-4 V alloy also referred to as titanium grade $V$ is analysed by Kumar et al. [23] under three different cooling systems, viz. dry, wet and cryogenic using coated AICrN /TiAIN tool. The Liquid Carbon Dioxide (LCO2) has been employed as a cryogenic coolant considering the economical aspect. Furthermore, Technique of Order Preference by Similarity to Ideal Solution (TOPSIS) approach has been adopted for optimizing the machining conditions to optimize the surface roughness and tool frank wear. According to the authors, it has been concluded that optimal machining takes place under LCO2 conditions along with low level of speed and feed rate. Osman et al. [34] analysed the properties of various concentrations of hexagonal boron nitride nanoparticles in MQL system for the process improvements of slot-milling of titanium alloy. Furthermore, PSO algorithm has been applied to improve energy-efficiency of the process. Gupta et al. [13] investigated nano-fluidbased MQL system for the machining of titanium alloy in order to improve the surface roughness of generated product. Also, the Adaptive Neuro-Fuzzy Inference System (ANFIS) was applied to predict the response. The machining performance of textured carbide tool in terms of tool wear, tool life, and surface roughness while turning of Ti$6 \mathrm{Al}-4 \mathrm{~V}$ alloy under three different lubrications, viz. dry turning, MQL turning using canola oil, and NMQL turning using graphene (1 wt\%) mixed in canola oil is investigated experimentally by Singh et al. [51]. The effect of cutting speed has been analysed. The various tool-wear forms, surface roughness, and lubrication tendency of graphene are examined by using tool maker's microscope, surface roughness analyser, Confocal Raman spectroscopy, SEM equipped with an energy-dispersive X-ray spectrometer (EDS), and optical microscope. It is reported that the use of graphene along with canola oil improved the performance of the textured tool and resulted in enhanced tool life simultaneously improving the surface finish. Singh et al. $[49,50]$ applied multi-attribute decision-making methods (MADMs) such as Analytic Hierarchy Process (AHP), TOPSIS, and Simple Additive Weighting (SAW) to optimize the turning of titanium alloy. Singh et al. $[49,50]$ employed the evolutionary algorithms such as PSO, Bacteria Foraging Optimization (BFO) and Teaching-Learning-Based Optimization (TLBO) to optimize the turning of titanium with upgraded MQL environment. Gupta et al. [14] applied 
Taguchi method with TOPSIS to optimize the turning of titanium alloy. Mishra et al. [28] experimentally investigated the performance of turning of Ti6Al4V alloy with laser textured tools under three different machining environments, viz. dry, vegetable oil-based MQL, and alumina suspended water-based nano-MQL. Four responses such as cutting forces, contact length, tool wear and chip adhesion over the rake face have been analysed. The results of plain and textured tools with the same machining parameters have been compared. It is observed that the textured tools along with the MQL environment have resulted in reduction of cutting forces, contact length, tool wear and chip adhesion over the rake face. It is reported that the limited advantage of using nano-fluids as nanoparticles get accumulated in the textured space. Mia et al. [27] applied six sigma methodology for finding out the optimized process parameters of the turning of hardened steel under various cooling considerations such as dry, flood cooling, $\mathrm{MQL}$, and solid lubrication with compressed air condition. RSM methodology has been applied for designing and analysing the experiments. Furthermore, regression equations are developed for finding out the optimum surface finish, keeping the process temperature minimum. It is reported that the improved quality surface is generated with dry cutting condition; however the process temperature is dispersive. The reduction in temperature is achieved with the MQL cutting conditions.

The applicability of several evolutionary algorithms to solve the complex problems of machining of titanium alloy in MQL environment is clearly evident from the above review. The manufacturing processes have become extremely complex owing to the recent technological advances. Today's manufacturing industry is trying to address the challenges such as growing needs for safety, reduced time-to-market that implies minimal manufacturing costs through the efficient use of the resources, and expected quality of highly customized products. Determining optimal process parameter settings critically influences productivity, quality, and cost of production. In order to avoid rework and to achieve the desired dimensions with the set tolerances, surface finesses, etc., the optimization of the process parameters is foremost important. Several problems of advanced manufacturing processes such as AWJM, EDM, and micro-machining have been already solved with contemporary algorithms, viz. firefly and PSO. The same problems have been solved with the socio-inspired algorithms such as $\mathrm{Cl}$ [46] and its significantly modified version referred to as Multi-Cl [46]. It has been observed that these algorithms performed exceedingly better as compared with the contemporary algorithms. Therefore, the performance of these algorithms can also be exploited for solving real-world optimization problem of turning of titanium alloy (Grade II) in MQL environment. Its several variations and significantly modified version referred to as Multi-Cl have been successfully applied for solving real-world optimization problem of Titanium alloy under MQL Environment. The performance responses such as tangential force $F_{c}$, tool wear $V_{\text {Bmax }}$ surface roughness $R_{a}$ and tool-chip contact length $L$ have been successfully optimized. The novelty and contribution of the current work is as follows: 1 . The suitability of variations of $\mathrm{Cl}$ and Multi-Cl algorithms for optimization of process parameters of turning of titanium alloy in $\mathrm{MQL}$ environment is successfully demonstrated and validated. 2. The solutions using variations of socio-inspired Cohort Intelligence $(\mathrm{Cl})$ algorithm and Multi- $\mathrm{Cl}$ are robust with reasonable computational cost. 3. Multi-Cl solutions are comparable with other variations of $\mathrm{Cl}$; however, it could yield minimum of $8 \%$ and maximum of $53 \%$ improvement as compared to contemporary algorithms, desirability and experimental approaches.

Rest of the paper is structured as follows: Sect. 2 in detail describes four problems of turning of titanium alloy in MQL environment, viz. minimization of cutting force $F_{c^{\prime}}$ surface roughness $R_{a}$, tool wear $V_{\mathrm{Bmax}}$, and tool chip contact length $L$. It includes importance of the problems and mathematical formulations. In Sect. 3, the solution methodologies are discussed and in Sect. 4 the results and comparison amongst several algorithms have been presented. Conclusions and future directions are provided at the end.

\section{Problem description and formulations}

Gupta et al. [16] performed turning of titanium alloy (Grade II) with cubic boron nitride tool in MQL environment. Cutting speed $V_{c}(\mathrm{~m} / \mathrm{min})$, feed rate $f(\mathrm{~mm} / \mathrm{rev})$ and approach angle $\emptyset$ (degrees) were considered as process parameters, while tangential force $F_{c}$, tool wear $V_{B \max }$, surface roughness $R_{a}$ and tool-chip contact length $L$ were process responses (refer to Fig. 1. A generic MQL schematic for turning process is presented in Fig. 1.

The cutting force $F_{c}$ depends on the depth of cut and feed rate $f$. The value of $F_{c}$ is directly proportional to the feed rate $f$, and is inversely proportional to the cutting speed $V_{c}$. The directional cutting forces also depend on the tool entering angles used [31]. As mentioned earlier, increase in the cutting forces is directly proportional to 
Fig. 1 Generic MQL schematic

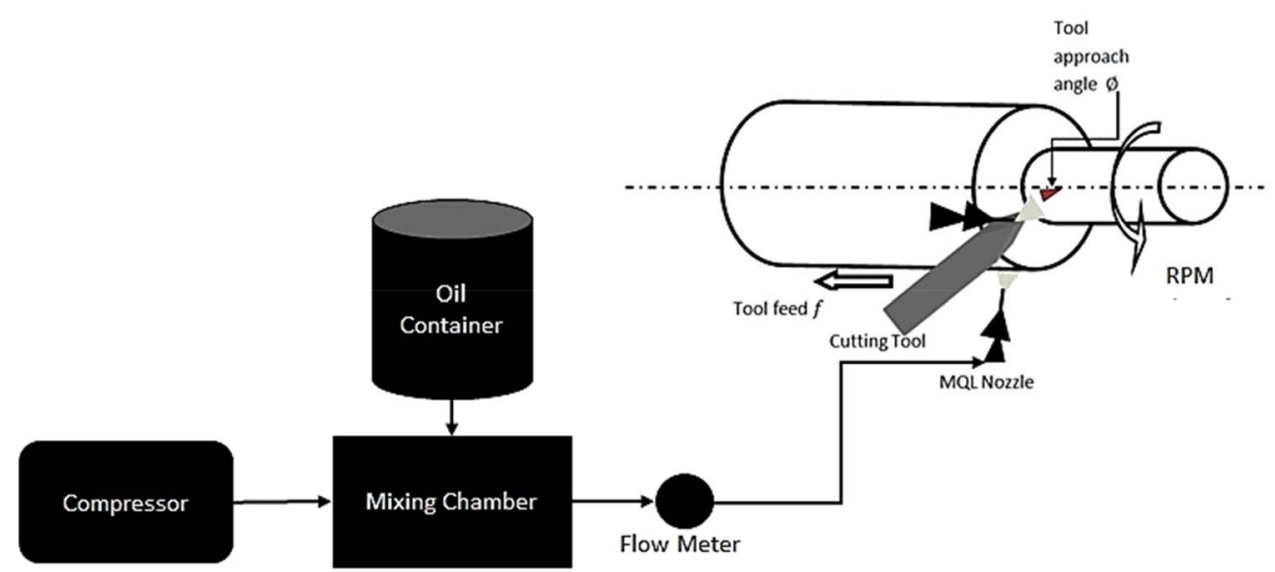

the feed rate $f$, whereas it carries inverse relationship with the cutting speed $V_{c}$. The tool angle $\emptyset$ also shows significant effect on the directional cutting forces. Higher cutting forces results into increased power consumption, and reduced tool life. To avoid this, cutting forces should be minimized. The relationship is as presented in Eq. 1. Titanium is a highly reactive metal. It is the major cause of poor machinability of titanium alloys. Flank wear $V_{\text {Bmax }}$ and excessive chipping on the tool flank edge are the major causes of the tool failure. Hence, to reduce the tool wear, low cutting speed $V_{c}$ is preferred [11]. According to Ghani et al. [12] cutting speed $V_{c}$ and depth of cut were the major causes for the failure of the cutting tools. The higher values of the cutting speeds, depth of cut and sharp tool angle $\emptyset$ increase the loading conditions on the tool. This increases the tool load, ultimately micro-cracks are developed and tool fails with the brittle fracture. Equation 2 defines the objective function of tool wear $V_{\text {Bmax }}$. The machining of titanium alloys results in the poor machinability and hence finishing processes must be employed. It is observed that the surface roughness $R_{a}$ for titanium alloys is a result of complexities involved in the machining associated with the built up edge formation, geometry and tool wear, temperature, tool coating, feed rate $f$, cutting speed $V_{c}$, approach angle $\emptyset$, and depth of cut [53]. Also, sub-effects like material phase transformations, and mechanical and thermal deformations during the machining processes have an impact over surface roughness $R_{a}$ which is directly proportional to the feed rate and inversely proportional to the cutting speed and depth of cut [31]. In order to achieve the better surface quality of machined titanium product, it is required to minimize the surface roughness $R_{a}$. Equation 3 describes the associated mathematical function. The effect of chip formation mechanism on the machining process is characterized by tool chip contact length $L$.
The chip and segmented chips have been observed [31]. In the literature, a strong correlation has been observed between the cutting forces $V_{c}$, the tool damage types, and the workpiece surface roughness. This confirms the relationship of the cutting parameters such as speed $V_{c}$, feed $f$, and the insert geometry such as tool angle $\emptyset$ on the tool condition and surface finish [43]. Hence it is important to minimize the tool chip contact length $L$. Equation 4 defines the associated mathematical formulation.

As stated above, in order to achieve better product quality with increased productivity and minimum cost, process parameters such as cutting speed $V c$, feed rate $f$ and approach angle $\emptyset$ should be optimized for the turning of titanium alloy (Grade II) which may yield into optimal values of cutting force $F c$, tool wear $V_{B \text { max }}$, surface roughness $R a$ and tool-chip contact length $L$ [13]. Gupta et al. $[13,14]$ performed the parametric optimization of the turning Titanium (Grade-II) alloys for $F C, V_{\mathrm{Bmax}}, R_{a}$, and $L$ using PSO and desirability analysis. In addition, confirmation experiments have also been performed. According to Gupta et al. $[13,14]$ the RSM technique has been used for analysis and design of experiments. The Box-Behnken design (BBD) approach has been adopted for developing the response models using RSM along with a total of seventeen experiments under MQL condition using Cubic Boron Nitride (CBN) cutting tool. The range of input parameters was selected such that higher material removal rate can be achieved. Based on the experimental data, the best fit equations to relate the responses, viz. $F c$, $V_{\mathrm{Bmax}}, R_{a}$, and $L$ with cutting parameters as $V_{c}, f$ and $\emptyset$ have been developed by method of regression analysis with the design expert software. The final regression equations (mathematical models) developed by Gupta et al. [15, 16] are given in Eqs. 1-4. These objective functions have been adopted in the current work 
Minimize $F_{c}=-202.01471+1.28250 \times V_{c}+3225 \times f_{c}-0.74167 \times \emptyset-9.4 \times V_{c} \times f$

Minimize $V_{\mathrm{Bmax}}=-0.27368+0.001575 \times V_{c}+2.4 \times f-0.0010833 \times \emptyset$

Minimize $R_{a}=-0.16294+0.001425 \times V_{c}+3.7 \times f-0.000416667 \times \emptyset$

Minimize $L=0.96302-0.00215931 \times V_{c}+0.92703 \times f+0.00152807 \times \emptyset$

The upper and lower limits for the each of the process parameters are as follows:

$200 \leq V_{c} \leq 300$,

$0.1 \leq f \leq 0.2$

$60 \emptyset \leq 90$

\section{Solution methodologies}

There are several nature inspired optimization algorithms which are broadly classified into bio-inspired, physicsbased and socio-inspired methods. The notable socioinspired methods are Ideology Algorithm [17], Election Algorithm [9], The League Championship Algorithm [19], Soccer League Competition Algorithm [29], Teaching Learning-Based Optimization [40], Cultural Evolution Algorithm [24], Social Learning Optimization [26], Anarchic Society Optimization [2] and Cl [22]. Recently, algorithm of $\mathrm{Cl}$ and its hybridized versions have been applied for solving several complex problems. Few of them are from domains such as healthcare [3], feature selection [4], etc. The framework of $\mathrm{Cl}$ [22], and Multi-Cl [45] methodologies have been concisely discussed here.

A cohort is a group of learning candidates. These candidates attempt to achieve the best possible individual behaviour through interaction and competition with other candidates in the cohort. This learning drives the candidates to evolve. The entire cohort is assumed to have saturated once when most of the candidates exhibit the similar behaviour and further learning from another is not possible. The $\mathrm{Cl}$ algorithms model the interactive and competitive behaviour of the candidates. The behaviour of every candidate is modelled as problem objective function associated. Every candidate iteratively attempts to achieve the best value of the objective function. This way the candidates evolve the objective function value and eventually the cohort. The cohort is assumed to be converged once all the candidates have the similar objective function

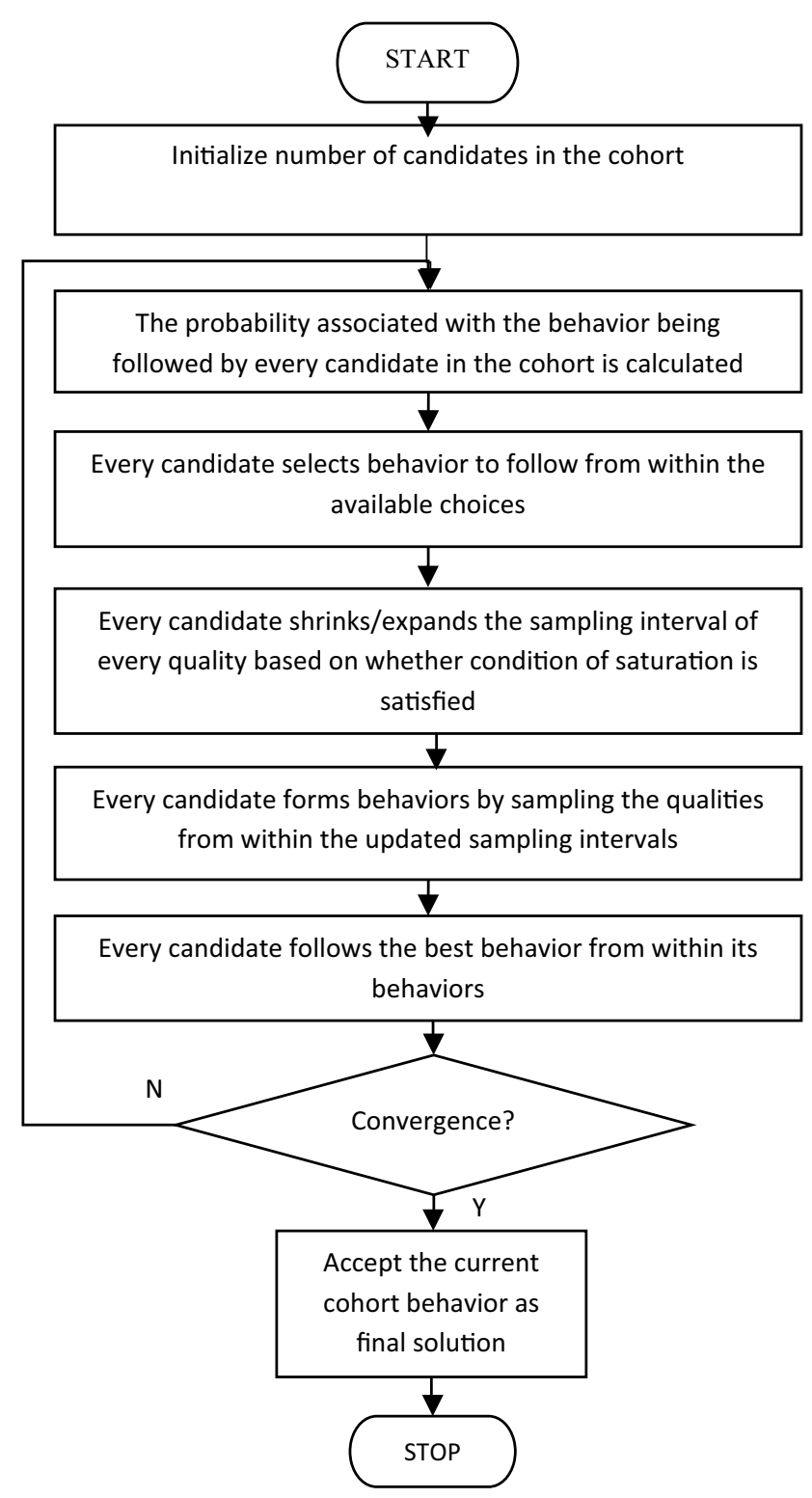

Fig. 2 Cohort intelligence (Cl) flowchart [22]

\section{SN Applied Sciences}


value and further learning is not possible. The best objective function value from the converged cohort is accepted as the final solution. The flowchart of the $\mathrm{Cl}$ algorithm is presented in Fig. 2. For detailed mathematical formulation refer to Kulkarni et al. [22]. Different variations of $\mathrm{Cl}$ algorithm have been proposed by Patankar and Kulkarni [35] based on the learning mechanism adopted. In the follow best approach, the candidate attempts to learn from the

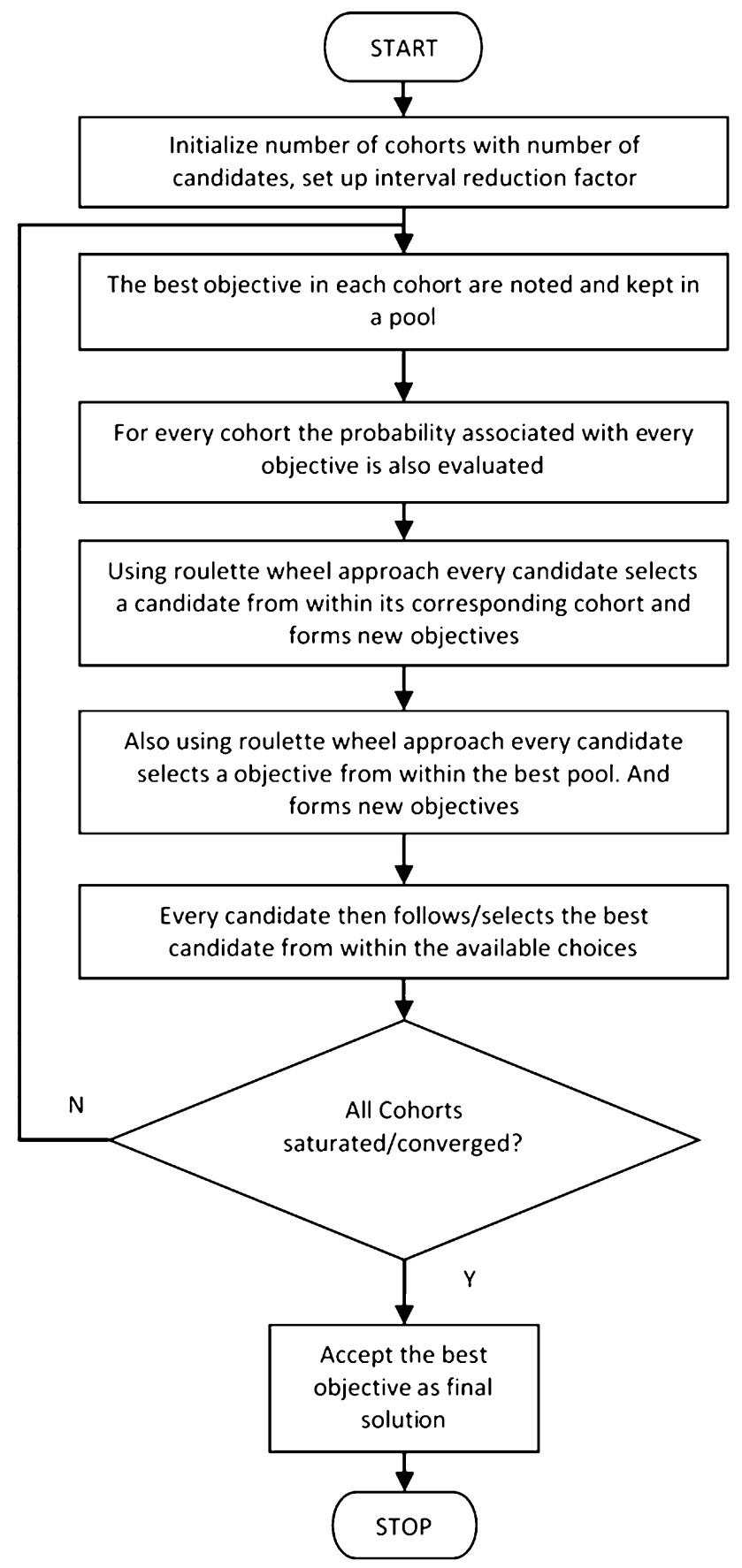

Fig. 3 Multi-Cl algorithm flowchart [15] one which has the best objective function value, in the follow better approach candidate attempts to learn from any of the other candidates with better function value. The Roulette wheel approach exploits the associated probabilistic rule and the alienation approach employs following any candidates excluding an isolated candidate.

It is important to mention that the $\mathrm{Cl}$ algorithm [3, 4,22 ] models the behaviour of the candidates in single cohort. Shastri and Kulkarni [45] proposed Multi-Cohort Intelligence (Multi-Cl) Algorithm in which interaction and competition among different cohorts is modelled. This intra- and inter-cohort learning behaviour helped the cohorts explore the search space more efficiently as well as local search. The probabilistic selection of the candidates from a pool of best objective function value candidates chosen from within all the cohorts along with the pool of every cohort is at the heart of the Multi-Cl algorithm. The step-by-step procedure with illustrative example is given in Shastri and Kulkarni [45]. The detailed flowchart is shown in Fig. 3.

\section{Results and discussion}

The variations of $\mathrm{Cl}$ and Multi- $\mathrm{Cl}$ algorithm were coded in MATLAB R2017 on Windows Platform with an Intel Core i3 processor and 4 GB RAM. The control parameters associated with the Multi-Cl and variations of $\mathrm{Cl}$ for solving the turning of titanium in MQL environment problem are listed in Table 1. These parameters are chosen based on the initial trials of the algorithms. Every problem was solved 30 times. In Table 2, best and mean solutions for Cutting Force $F_{c}$, Tool Wear $V_{\mathrm{Bmax}}$, Surface Roughness $R_{a}$ and Tool Chip Contact Length $L$ along with associated standard deviation and run time obtained using variations of $\mathrm{Cl}$, and Multi- $\mathrm{Cl}$ are shown. These solutions have been compared with experimental work, desirability approach and PSO algorithm as shown in Table 3. Optimum values of cutting speed $V_{c}$, feed $f$, and the tool angle $\emptyset$ associated with the best values (refer Table 3 for variations of $\mathrm{Cl}$, and Multi- $\mathrm{Cl}$ algorithms are presented in Table 4.

In the method of PSO, a swarm of solutions modify their positions in the search space. Every particle has certain velocity with which it moves in the search space based on the local best solution in the close neighbourhood as well as the global best solution in the entire swarm. According to [15, 16, 45], the algorithm of PSO may not be efficient for solving inseparable, nonlinear real-world problems. It is evident from Eq. 1 that the considered problem is inseparable, multimodal and nonlinear in nature and hence algorithm needs balanced exploration and exploitation abilities to find 
Table 1 Parameter setting for multi- $\mathrm{Cl}$ and variations of $\mathrm{Cl}$

\begin{tabular}{lll}
\hline Solution methodology & Parameter & Stopping criteria \\
\hline Multi-Cl & No. of Cohorts $=3$ & Function value less than $10^{-16}$ \\
& No. of candidates $=5$ & \\
& Value of Reduction factor $=0.99$ & \\
& Behavioural Variations for best candi- \\
& dates $=5$ and for rest of the candi- \\
& dates $=10$ \\
Variations of $\mathrm{Cl}$ & No. of candidates $=5$ & \\
& Value of Reduction factor $=0.99$ & \\
\hline
\end{tabular}

Table 2 Statistical solutions to problems using variations of $\mathrm{Cl}$ and multi-Cl

\begin{tabular}{|c|c|c|c|c|c|c|}
\hline \multirow{3}{*}{$\begin{array}{l}\text { Mechani- } \\
\text { cal } \\
\text { machining } \\
\text { process }\end{array}$} & \multirow{3}{*}{$\begin{array}{l}\text { Objective } \\
\text { function }\end{array}$} & \multicolumn{5}{|c|}{ Algorithms applied } \\
\hline & & \multicolumn{4}{|l|}{ Variations of $\mathrm{Cl}$} & \multirow[t]{2}{*}{ Multi-Cl } \\
\hline & & Roulette wheel & Follow best & $\begin{array}{l}\text { Follow } \\
\text { better }\end{array}$ & Alienation & \\
\hline & $F_{c}$ & & & & & \\
\hline \multirow{19}{*}{$\begin{array}{l}\text { Turning } \\
\text { in MQL } \\
\text { environ- } \\
\text { ment }\end{array}$} & Mean & 122.34 & 122.35 & 122.24 & 122.27 & 122.23 \\
\hline & SD & 0.05 & 2.95 & 0.00 & 0.01 & 0.01 \\
\hline & Best & 122.28 & 122.24 & 122.24 & 122.25 & 122.23 \\
\hline & $\begin{array}{l}\text { Run time } \\
\text { (Sec) }\end{array}$ & 0.32 & 0.27 & 0.57 & 1.07 & 0.64 \\
\hline & \multicolumn{6}{|l|}{$V_{B \max }$} \\
\hline & Mean & 0.18 & 0.19 & 0.18 & 0.18 & 0.18 \\
\hline & SD & 0.00 & 0.01 & 0.00 & 0.00 & 0.00 \\
\hline & Best & 0.18 & 0.18 & 0.18 & 0.18 & 0.18 \\
\hline & $\begin{array}{l}\text { Run time } \\
\text { (Sec) }\end{array}$ & 0.49 & 0.28 & 0.58 & 1.40 & 0.59 \\
\hline & \multicolumn{6}{|l|}{$L$} \\
\hline & Mean & 0.49 & 0.49 & 0.49 & 0.49 & 0.49 \\
\hline & SD & 0.00 & 0.00 & 0.00 & 0.00 & 0.00 \\
\hline & Best & 0.49 & 0.49 & 0.49 & 0.49 & 0.49 \\
\hline & $\begin{array}{l}\text { Run time } \\
\text { (Sec) }\end{array}$ & 0.32 & 0.27 & 0.57 & 1.17 & 0.57 \\
\hline & \multicolumn{6}{|l|}{$R_{a}$} \\
\hline & Mean & 0.46 & 0.46 & 0.46 & 0.46 & 0.46 \\
\hline & SD & 0.00 & 0.00 & 0.00 & 0.00 & 0.00 \\
\hline & Best & 0.45 & 0.46 & 0.45 & 0.45 & 0.45 \\
\hline & $\begin{array}{l}\text { Run time } \\
\text { (Sec) }\end{array}$ & 0.54 & 0.27 & 0.58 & 1.32 & 0.58 \\
\hline
\end{tabular}

Mean mean solution, SD standard-deviation of mean solution, Best best solution, runtime mean runtime

Table 3 Comparison of Algorithms

\begin{tabular}{lcclrrrrr}
\hline $\begin{array}{l}\text { Objective } \\
\text { Function }\end{array}$ & $\begin{array}{l}\text { PSO Gupta } \\
\text { et al. [15] }\end{array}$ & $\begin{array}{l}\text { Desirability } \\
\text { Gupta et al. [15] }\end{array}$ & $\begin{array}{l}\text { Experimental } \\
\text { Gupta et al. [15] }\end{array}$ & Roulette Wheel & Follow Best & Follow Better & Alienation & Multi-Cl \\
\hline$F_{c}$ & 132.52 & 138.68 & 133.45 & 122.28 & 122.24 & 122.24 & 122.25 \\
$V_{b}$ & 0.31 & 0.38 & 0.34 & 0.18 & 0.18 & 0.18 & 122.23 \\
$L$ & 0.793 & 0.853 & 0.811 & 0.49 & 0.49 & 0.49 & 0.18 \\
$R_{a}$ & 0.53 & 0.60 & 0.56 & 0.45 & 0.46 & 0.45 & 0.49 \\
\hline
\end{tabular}


Table 4 Optimum Values of $V_{c^{\prime}}$ $f$, and $\emptyset$ for variations of $\mathrm{Cl}$ and Multi-Cl

\begin{tabular}{|c|c|c|c|c|c|c|}
\hline \multirow{3}{*}{$\begin{array}{l}\text { Mechanical } \\
\text { machining } \\
\text { process }\end{array}$} & \multirow{3}{*}{$\begin{array}{l}\text { Objective } \\
\text { function }\end{array}$} & \multicolumn{5}{|c|}{ Algorithms applied } \\
\hline & & \multicolumn{4}{|l|}{ Variations of $\mathrm{Cl}$} & \multirow[t]{2}{*}{ Multi-C } \\
\hline & & Roulette wheel & Follow best & Follow better & Alienation & \\
\hline \multirow{16}{*}{$\begin{array}{l}\text { Turning in } \\
\text { MQL Envi- } \\
\text { ronment }\end{array}$} & $F_{c}$ & & & & & \\
\hline & $V_{c}$ & 200.10 & 200 & 200 & 200 & 200 \\
\hline & $f$ & 0.1 & 0.1 & 0.1 & 0.1 & 0.1 \\
\hline & $\emptyset$ & 89.99 & 89.99 & 89.99 & 89.99 & 89.99 \\
\hline & $V_{\mathrm{Bmax}}$ & & & & & \\
\hline & $V_{c}$ & 200.00 & 200 & 200.00 & 200.00 & 200 \\
\hline & $f$ & 0.1 & 0.1 & 0.1 & 0.1 & 0.1 \\
\hline & $\emptyset$ & 89.99 & 89.99 & 89.99 & 89.99 & 89.98 \\
\hline & $L$ & & & & & \\
\hline & $V_{c}$ & 299.99 & 300 & 300 & 300 & 300 \\
\hline & $f$ & 0.1 & 0.1 & 0.1 & 0.1 & 0.1 \\
\hline & $\emptyset$ & 60.07 & 60.01 & 60 & 60 & 60.02 \\
\hline & $R_{a}$ & & & & & \\
\hline & $V_{c}$ & 200 & 200 & 200 & 200 & 200 \\
\hline & $f$ & 0.1 & 0.1 & 0.1 & 0.1 & 0.1 \\
\hline & $\emptyset$ & 83.71 & 83.12 & 83.69 & 83.71 & 86.02 \\
\hline
\end{tabular}

global optimum solution. It is evident from Table 3 that the Multi-Cl algorithm outperformed PSO in terms of solution quality as Multi-Cl has intra- as well as intergroup learning mechanism which makes the algorithm stronger in exploitation. Multi-Cl solutions are more robust with less standard deviation when compared with the follow best and roulette wheel approach of variations of $\mathrm{Cl}$ (refer Table 2). In addition, the run time for alienation approach is more when compared with other variations of $\mathrm{Cl}$ and Multi- $\mathrm{Cl}$. In addition, Multi-Cl outperformed experimental and desirability approach (refer Table 3). For cutting force $F_{c}$, tool wear $V_{\text {Bmax }}$, toolchip contact length $L$ and surface roughness $R_{a}$, the best solutions in every learning attempt for each cohort of Multi- $\mathrm{Cl}$ and variations of $\mathrm{Cl}$ are plotted in Fig. 4 (a), (b), (c) and (d), respectively.

In follow best approach, candidates randomly select the behaviour and the associated characteristics in the first attempt. For every following learning attempt, the candidates follow the behaviour of the best candidate and at the same time best candidate also explores the better solution due to which candidates do not get trapped in local minimum and gives better mix of exploration and exploitation. This behaviour can be clearly seen from Fig. 4. It is an important observation that follows better variation of $\mathrm{Cl}$ converged to optimum solution; however, the fluctuating pattern highlighted the multimodality of every function. The efforts of the candidates in jumping out of the local minima are evident from Fig. 4. Because of intra- and inter-learning group mechanisms, Multi-Cl could exhibit faster convergence for every cohort as compared to other approaches. In follow best approach, candidates follow the best candidate from the cohort. So, there is a possibility of solutions getting trapped in local minima. It could be observed in the convergence plot given in Fig. 4. As learning progresses, the best candidate jumps out of local minima and eventually for all candidates the global minimum is obtained. It is important to mention that for turning of titanium alloy in MQL environment, Multi- $\mathrm{Cl}$ achieved $8 \%$ minimization of cutting force $F_{c}, 42 \%$ minimization of tool wear $V_{B \max }, 38 \%$ minimization of tool-chip contact length $L$, and $15 \%$ minimization of surface roughness $R_{a}$ when compared with PSO. For desirability and experimental approaches, $12 \%$ and $8 \%$ minimization of cutting force $F_{c}, 42 \%$ and $47 \%$ minimization of tool wear $V_{\text {Bmax }}$ $53 \%$ and $40 \%$ minimization of tool-chip contact length $L$, and $15 \%$ and $20 \%$ minimization of surface roughness $R_{a}$ were attained, respectively (refer Table 3 .

As stated in Sect. 2, it is important to find out the optimum combination of cutting speed $V_{c}$, feed $f$, and the tool angle $\emptyset$ for minimizing the cutting force $F_{c^{\prime}}$, tool wear $V_{\mathrm{Bmax}}$ tool-chip contact length $L$ and surface roughness $R_{a}$. It is clear from Eq. that there exists nonlinear relation and interrelation between the parameters affecting the responses. This makes the problem complex. It is critical in the manufacturing industry to achieve the required level of surface roughness. Furthermore, nowadays the industry is adopting the sustainable manufacturing approach keeping the impact on the environment minimum. In the present 


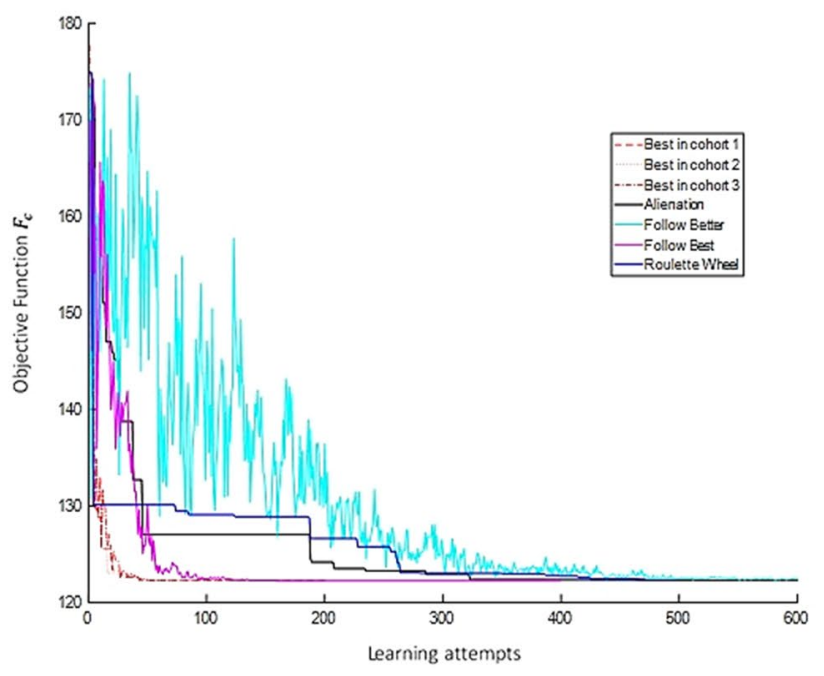

(a) Best solutions for Cutting Force $F_{c}$

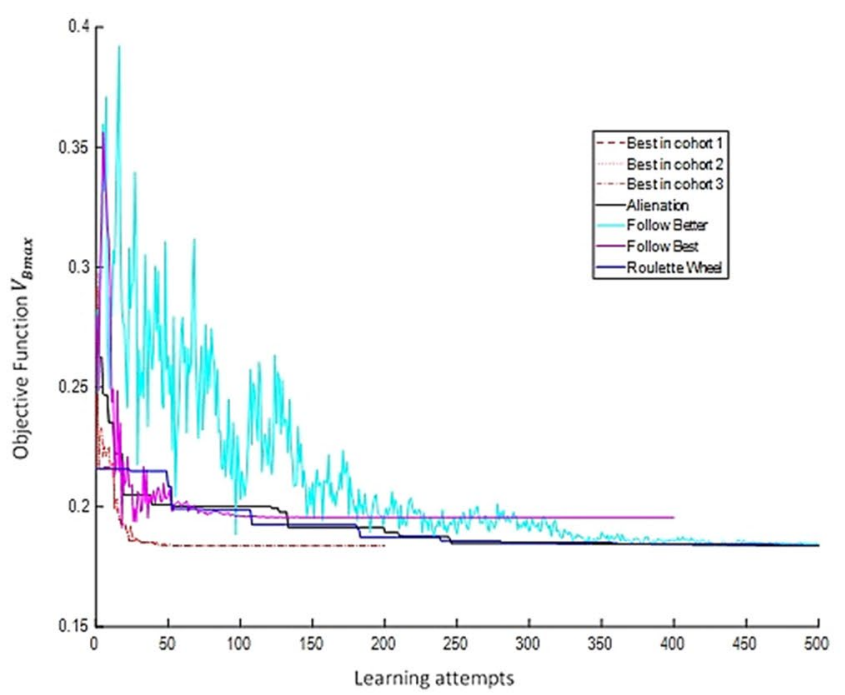

(b) Best solution for Tool Wear $V_{B \max }$

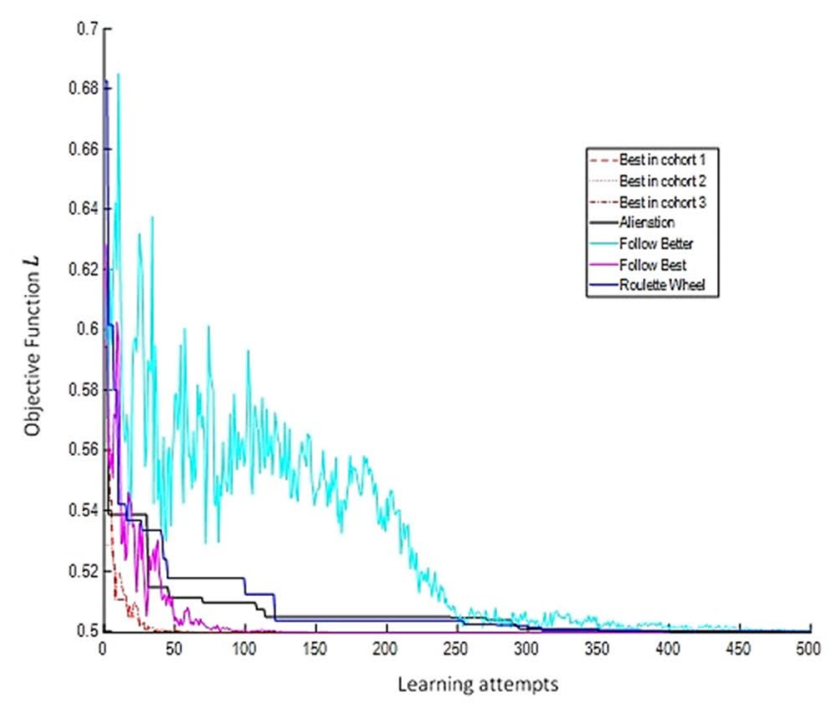

(c) Best solution for Tool-Chip Contact Length $L$

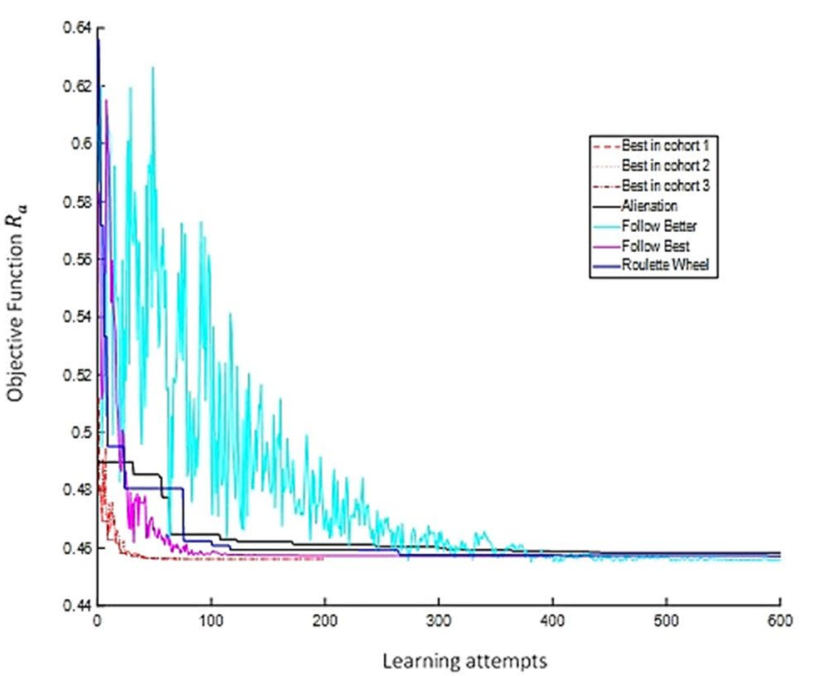

(d) Best solution for Surface Roughness $R_{a}$

Fig. 4 Convergence plots of best solutions

study, the optimum combination of parameters for the sustainable manufacturing approach, resulting in the significantly improved results as compared with the existing literature solution, has been achieved (refer Table 4). The industry can directly adopt these parameters for achieving the desired surface finish, keeping the cutting forces and tool wear minimum. However, to make the problem more realistic and industry oriented, real-world constraints on productivity, machining time, desired material removal rate, cutting power consumption, etc., could be considered. Also, multi-objective optimization approach could be adopted.

\section{Conclusions and future directions}

This paper presents the application of socio-inspired optimization techniques, viz. $\mathrm{Cl}$ and its variations as well as Multi-Cl for solving real-life machining optimization problem of titanium alloy (Grade II) in MQL environment. The objective functions are minimization of cutting force $F_{C}$, tool wear $V_{B \max }$, tool-chip contact length $L$ and surface roughness $R_{a}$. The solutions obtained using follow better, follow best, alienation \& roulette wheel approaches of $\mathrm{Cl}$, and Multi- $\mathrm{Cl}$ algorithms have been compared with the experimental results reported in the literature as well as with contemporary evolutionary algorithm PSO. Multi-Cl successfully outperformed experimental results, 
desirability approach and PSO in terms of solution quality. Since in Multi-Cl, several cohorts interact and compete with one another, it is observed that the computational time for variations of $\mathrm{Cl}$ is lower as compared to Multi-Cl algorithm. However, the solution quality using Multi-Cl is better as compared to PSO and experimental approach. In addition, the standard deviation of Multi-Cl was comparatively lower which exhibited its robustness. This is because Multi-Cl exhibits better exploration and exploitation capabilities as every candidate competes with its individual local best solution along with the best solution chosen from the other cohorts. It is important to mention that for turning of titanium alloy in MQL environment, Multi-Cl achieved $8 \%$ minimization of cutting force $F_{c^{\prime}} 42 \%$ minimization of tool wear $V_{\mathrm{Bmax}}, 38 \%$ minimization of toolchip contact length $L$, and $15 \%$ minimization of surface roughness $R_{a}$ when compared with PSO. For desirability and experimental approaches, $12 \%$ and $8 \%$ minimization of cutting force $F_{c}, 42 \%$ and $47 \%$ minimization of tool wear $V_{\text {Bmax }}, 53 \%$ and $40 \%$ minimization of tool-chip contact length $L$, and $15 \%$ and $20 \%$ minimization of surface roughness $R_{a}$ were attained, respectively.

In the future, the optimized parameters could be directly adopted by the manufacturing industry for achieving the desired surface finish, keeping the cutting forces and tool wear minimum. Furthermore, real-world constraints on productivity, machining time, desired material removal rate, cutting power consumption, etc., could be considered. In addition, constrained handling methods could be incorporated in $\mathrm{Cl}$ as well as in Multi-Cl to solve hard constrained mixed variable problems from the sustainable manufacturing domain.

\section{Compliance with ethical standards}

Conflict of interest All authors have declare that they have no conflict of interest.

Open Access This article is licensed under a Creative Commons Attribution 4.0 International License, which permits use, sharing, adaptation, distribution and reproduction in any medium or format, as long as you give appropriate credit to the original author(s) and the source, provide a link to the Creative Commons licence, and indicate if changes were made. The images or other third party material in this article are included in the article's Creative Commons licence, unless indicated otherwise in a credit line to the material. If material is not included in the article's Creative Commons licence and your intended use is not permitted by statutory regulation or exceeds the permitted use, you will need to obtain permission directly from the copyright holder. To view a copy of this licence, visit http://creativecommons .org/licenses/by/4.0/.

\section{References}

1. Abidi MH, Al-Ahmari AM, Umer U, Rasheed MS (2018) Multiobjective optimization of micro-electrical discharge machining of nickel-titanium-based shape memory alloy using MOGA-II. Measurement 125:336-349

2. Ahmadi-Javid A, Hooshangi-Tabrizi $P$ (2017) Integrating employee timetabling with scheduling of machines and transporters in a job-shop environment: a mathematical formulation and an Anarchic Society Optimization algorithm. Comput Oper Res 84:73-91

3. Aladeemy M, Adwan L, Booth A, Khasawneh MT, Poranki S (2020) New feature selection methods based on opposition-based learning and self-adaptive cohort intelligence for predicting patient no-shows. Appl Soft Comput 86:105866

4. Aladeemy M, Tutun S, Khasawneh MT (2017) A new hybrid approach for feature selection and support vector machine model selection based on self-adaptive cohort intelligence. Expert Syst Appl 88:118-131

5. Al-Ahmari AMA, Rasheed MS, Mohammed MK, Saleh T (2016) A hybrid machining process combining Micro-EDM and laser beam machining of Nickel-Titanium-Based shape memory alloy. Mater Manuf Processes 31(4):447-455

6. Chandrasekaran M, Muralidhar M, Krishna CM, Dixit US (2010) Application of soft computing techniques in machining performance prediction and optimization: a literature review. Int J Adv Manuf Technol 46(5-8):445-464

7. Darwish SM (2000) Machining of difficult-to-cut materials with bonded tools. Int J Adhes Adhes 20(4):279-289

8. DeGarmo EP, Black JT, Kohser RA, Klamecki BE (1997) Materials and process in manufacturing. Prentice Hall, Upper Saddle River

9. Emami H, Derakhshan F (2015) Election algorithm: a new sociopolitically inspired strategy. AI Commun 28(3):591-603

10. Ezugwu EO (2005) Key improvements in the machining of difficult-to-cut aerospace superalloys. Int J Mach Tools Manuf 45(12-13):1353-1367

11. Fujiwara J, Arimoto T, Tanaka K (2011) High speed milling of titanium alloy. In: Advanced materials research, vol 325, pp 387-392. Trans Tech Publications Ltd.

12. Ghani JA, Haron CHC, Hamdan SH, Said AYM, Tomadi SH (2013) Failure mode analysis of carbide cutting tools used for machining titanium alloy. Ceram Int 39(4):4449-4456

13. Gupta A, Kumar R, Kumar H, Garg H (2020a) Optimization of MQL machining parameters using combined Taguchi and TOPSIS method. In: Krolczyk G, Prakash C, Singh S, Davim J (eds) Advances in intelligent manufacturing. Lecture Notes in Mechanical Engineering. Springer, Singapore

14. Gupta MK, Mia M, Pruncu Cl, Khan AM, Rahman MA, Jamil M, Sharma VS (2020) Modeling and performance evaluation of $\mathrm{Al}_{2} \mathrm{O}_{3}, \mathrm{MoS}_{2}$ and graphite nanoparticle-assisted MQL in turning titanium alloy: an intelligent approach. J Braz Soc Mech Sci Eng 42:1-21

15. Gupta MK, Sood PK, Sharma VS (2016) Machining parameters optimization of titanium alloy using response surface methodology and particle swarm optimization under minimumquantity lubrication environment. Mater Manuf Processes 31(13):1671-1682

16. Gupta MK, Sood PK, Sharma VS (2016) Optimization of machining parameters and cutting fluids during nano-fluid based minimum quantity lubrication turning of titanium alloy by using evolutionary techniques. J Clean Prod 135:1276-1288

17. Hong SY, Markus I, Jeong WC (2001) New cooling approach and tool life improvement in cryogenic machining of titanium alloy Ti-6Al-4V. Int J Mach Tools Manuf 41(15):2245-2260 
18. Inagaki I, Takechi T, Shirai Y, Ariyasu N (2014) Application and features of titanium for the aerospace industry. Nippon Steel Sumitomo Metal Tech Rep 106(106):22-27

19. Kashan $\mathrm{AH}$ (2011) An efficient algorithm for constrained global optimization and application to mechanical engineering design: league championship algorithm (LCA). Comput Aided Des 43(12):1769-1792

20. Khettabi R, Fatmi L, Masounave J, Songmene V (2013) On the micro and nanoparticle emission during machining of titanium and aluminum alloys. CIRP J Manuf Sci Technol 6(3):175-180

21. Kishawy HA, Hosseini A (2019) Machining difficult-to-cut materials. Mater Form Mach Tribol 5:10

22. Kulkarni AJ, Durugkar IP, Kumar M (2013) Cohort intelligence: a self supervised learning behavior. In: 2013 IEEE international conference on systems, man, and cybernetics, pp 1396-1400. IEEE

23. Kumar S (2020) Multi-response optimization of Ti-6Al-4V milling using AICrN/TiAIN coated tool under cryogenic cooling. J Prod Syst Manuf Sci 1(1):4-4

24. Kuo HC, Lin CH (2013) Cultural evolution algorithm for global optimizations and its applications. J Appl Res Technol 11(4):510-522

25. Leyens C, Peters M (2003) Titanium and titanium alloys: fundamentals and applications. Wiley, London

26. Liu ZZ, Chu DH, Song C, Xue X, Lu BY (2016) Social learning optimization (SLO) algorithm paradigm and its application in QoS-aware cloud service composition. Inf Sci 326:315-333

27. Mia M, Gupta MK, Pruncu Cl, Sen B, Khan AM, Jamil M, Rahman MA (2020) Six sigma optimization of multiple machining characteristics in hard turning under dry, flood, MQL and solid lubrication. J Prod Syst Manuf Sci 1(1):6-6

28. Mishra SK, Ghosh S, Aravindan S (2020) Machining performance evaluation of Ti6Al4V alloy with laser textured tools under MQL and nano-MQL environments. J Manuf Process 53:174-189

29. Moosavian N (2015) Soccer league competition algorithm for solving knapsack problems. Swarm Evol Comput 20:14-22

30. Mukherjee I, Ray PK (2006) A review of optimization techniques in metal cutting processes. Comput Ind Eng 50(1-2):15-34

31. Niknam SA, Khettabi R, Songmene V (2014) Machinability and machining of titanium alloys: a review. In: Machining of titanium alloys, pp 1-30. Springer, Berlin

32. Schauerte $O$ (2002) Titanium and titanium alloys. Wiley, Weinheim, $\mathrm{p} 477$

33. Oliaei SNB, Karpat $Y$ (2016) Investigating the influence of built-up edge on forces and surface roughness in micro scale orthogonal machining of titanium alloy Ti6Al4V. J Mater Process Technol 235:28-40

34. Osman KA, Yılmaz V, Ünver HÖ, Şeker U, Kiliç SE (2020) Slot milling of titanium alloy with hexagonal boron nitride and minimum quantity lubrication and multi-objective process optimization for energy efficiency. J Clean Prod 120:739

35. Patankar NS, Kulkarni AJ (2018) Variations of cohort intelligence. Soft Comput 22(6):1731-1747

36. Pervaiz S, Anwar S, Qureshi I, Ahmed N (2019) Recent advances in the machining of titanium alloys using minimum quantity lubrication (MQL) based techniques. Int J Prec Eng Manuf Green Technol 6(1):133-145

37. Pramanik A, Islam MN, Basak AK, Dong Y, Littlefair G, Prakash C (2019) Optimizing dimensional accuracy of titanium alloy features produced by wire electrical discharge machining. Mater Manuf Process 34(10):1083-1090

38. Ramulu M, Isvilanonda V, Pahuja R, Hashish M (2016) Experimental investigation of abrasive waterjet machining of titanium graphite laminates. Int J Autom Technol 10(3):392-400

39. Rao RV, Pawar PJ, Davim JP (2010) Parameter optimization of ultrasonic machining process using nontraditional optimization algorithms. Mater Manuf Process 25(10):1120-1130

40. Rao RV, Savsani VJ, Vakharia DP (2011) Teaching-learningbased optimization: a novel method for constrained mechanical design optimization problems. Comput Aided Des 43(3):303-315

41. Revuru RS, Zhang JZ, Posinasetti NR, Kidd T (2018) Optimization of titanium alloys turning operation in varied cutting fluid conditions with multiple machining performance characteristics. Int J Adv Manuf Technol 95(1-4):1451-1463

42. Sahu AK, Mahapatra SS (2019) Optimization of electrical discharge machining of titanium alloy (Ti6Al4V) by grey relational analysis based firefly algorithm. In: Additive manufacturing of emerging materials, pp 29-53. Springer, Cham

43. Sandvik Coromant (Firm) (1994) . Modern metal cutting: a practical handbook. Sandvik Coromant

44. Sharma AK, Tiwari AK, Dixit AR (2016) Effects of Minimum Quantity Lubrication (MQL) in machining processes using conventional and nanofluid based cutting fluids: a comprehensive review. J Clean Prod 127:1-18

45. Shastri AS, Kulkarni AJ (2018) Multi-cohort intelligence algorithm: an intra-and inter-group learning behaviour based socioinspired optimisation methodology. Int J Parallel Emergent Distrib Syst 33(6):675-715

46. Shastri AS, Nargundkar A, Kulkarni AJ, Sharma KK (2020) Multicohort intelligence algorithm for solving advanced manufacturing process problems. Neural Comput Appl 5:1-21

47. Shokrani A, Al-Samarrai I, Newman ST (2019) Hybrid cryogenic MQL for improving tool life in machining of Ti-6Al-4V titanium alloy. J Manuf Process 43:229-243

48. Shokrani A, Dhokia V, Newman ST (2016) Investigation of the effects of cryogenic machining on surface integrity in CNC end milling of Ti-6Al-4V titanium alloy. J Manuf Process 21:172-179

49. Singh G, Pruncu Cl, Gupta MK, Mia M, Khan AM, Jamil M, Sharma VS (2019) Investigations of machining characteristics in the upgraded MQL-assisted turning of pure titanium alloys using evolutionary algorithms. Materials 12(6):999

50. Singh R, Dureja JS, Dogra M, Randhawa JS (2019) Optimization of machining parameters under MQL turning of Ti-6Al-4V alloy with textured tool using multi-attribute decision-making methods. World J Eng 5:10

51. Singh R, Dureja JS, Dogra M, Gupta MK, Mia M, Song Q (2020) Wear behavior of textured tools under graphene-assisted minimum quantity lubrication system in machining Ti-6Al-4V alloy. Tribol Int 145:106183

52. Tamang SK, Chandrasekaran M, Sahoo AK (2018) Sustainable machining: an experimental investigation and optimization of machining Inconel 825 with dry and MQL approach. J Braz Soc Mech Sci Eng 40(8):374

53. Ulutan D, Ozel T (2011) Machining induced surface integrity in titanium and nickel alloys: A review. Int J Mach Tools Manuf 51(3):250-280

Publisher's Note Springer Nature remains neutral with regard to jurisdictional claims in published maps and institutional affiliations. 